\title{
ОБЩЕНИЕ. ДЕЯТЕЛЬНОСТЬ. КОММУНИКАЦИЯ
}

\begin{abstract}
С.В. Лебедева
Современный уровень научного мышления не позволяет исследованию носить только описательный характер, так как выявление структуры изучаемого предмета является необходимым аспектом его системного анализа. Без такого анализа останется неясной связь исследуемого предмета с другими компонентами системы, его взаимоотношения с ними, соподчиненность.

Поэтому, с нашей точки зрения, вопрос о содержании общения необходимо рассматривать в соотношении с такими понятиями как деятельность, коммуникация, понимание, которые тесно связаны между собой.

Так, по определению В.Н. Сагатовского, общение - понимаемое на категориальном уровне - это одна из сущностных сторон человеческой жизни, без него нет человеческой целостности $[1$, с. 79]. Данный тезис конкретизирует Б.Ф. Ломов, отмечая, что «общение обеспечивает формирование общности индивидов, выполняющих совместную деятельность» (см.: [3, с. 284]). Это не просто деятельность по созданию предмета, в котором человек пытается запечатлеть самого себя. Это взаимная деятельность, взаимодействие свободно участвующих в процессе равноправных партнеров, основанное на взаимопонимании. Так понятая деятельность, по мнению В.А. Лекторского, должна распространяться не только на взаимодействие между людьми, но и на взаимодействие между человеком и природой в «незапрограммированном диалоге» [4, с. 62].

Исходя из вышеизложенного, нельзя не согласиться с высказыванием М.С. Кагана о том, что деятельность человека не следует сводить к
\end{abstract}

Актуальні проблеми духовності

(Відп. ред.: Я.В. Шрамко)

Кривий Ріг (2007), 350-359 
его предметной деятельности и тогда «общение естественно впишется в это целокупное и разностороннее проявление человеческой активности» $[3$, с. 124].

Данное утверждение мы попытаемся обосновать в этой статье на основе анализа вышеназванных понятий в их взаимосвязи.

Проблема соотношения деятельности и общения обсуждалась в отечественной философской литературе - как советской, так и постсоветской - с конца 60-х гг. ХХ в. Анализ литературы, посвященной ей, показывает, что среди исследователей отсутствует единство взглядов по вопросам сущности деятельности и общения, характеру их соотношения. В этом отношении показательным является сборник «Деятельность: теории, методология, проблемы», в котором собраны статьи крупных советских философов и психологов.

Так, по мнению А.В.Брушлинского, основным способом взаимодействия человека с миром является деятельность, осуществляемая на том или ином уровне общения [1, с. 129]. Ее субъект-человечество в целом, представляющее собой противоречивое неразрывное единство субъектов меньшего масштаба, т.е. различных социальных классов, групп, наций, индивидов, взаимодействующих друг с другом. В таком смысле каждая личность является субъектом, но субъект не сводится, конечно, к личности. Вместе с тем субъектом могут быть только люди, а не животные и не машины.

С ним согласен Н.С. Злобин, который считает, что деятельность, как методологический принцип, служит раскрытию специфики социальной формы движения материи, способа существования человека, который состоит в том, что человек не просто адаптируется к миру, а изменяет его в соответствии со своими интересами и потребностями, т. е. создает свой, социально обусловленный, человеческий мир, включая мир его собственных отношений - социальную действительность. Человек здесь выступает, следовательно, в качестве субъекта. Эту-то субъектную характеристику человека и высвечивает принцип деятельности $[1$, с. 112$]$.

В.С.Швырев высказывает в своей статье, хотя и недостаточно определенно, неудовлетворенность сведением деятельности к субъектнообъектным отношениям, только к преобразованию объективной реальности; им намечается возможность включения в деятельность «способности самоизменения», «мира человеческой субъективности», говорится о том, что такое преобразование собственного мира включает общение, понимание, диалог и т. д. $([1$, с. 6,15$])$.

Дискуссия о деятельности не исчерпывается общими проблемами. 
Важным является вопрос, как соотносятся конкретно-научные теории деятельности (например, в психологии) с ее философской концепцией. В лице В.В. Давыдова, например, мы находим страстного защитника универсализации понятия деятельности, т.е. «монизма». При таком подходе деятельность, понимаемую как субъектно-объектное отношение, автор объявляет главным и основным понятием, всеобщей «клеточкой», в которой концентрированно отражены всеобщий способ и специфика человеческой жизни. Общение же как процессуальное выражение их общественных отношений лишь оформляет в определенных рамках содержание деятельности. Общение людей в таком случае может существовать лишь в процессе реализации деятельности.

$\mathrm{C}$ точки зрения принципа восхождения от абстрактного к конкретному деятельность тем самым является, по его мнению, более существенной категорией чем общение [1, с.148]. С этим не согласен В.Н. Сагатовский, который считает, что это «позиция делового человека: создайте только подходящие условия труда - все остальное приложится». Где уж тут говорить о культуре общения, о понимании, о собственной внутренней жизни, самоценности духовности. Автор считает, что субъектно-объектное преобразование само по себе ни генетически, ни тем более функционально не может быть основой для вывода и объяснения всей сложности человеческого бытия [1, с.201]. В подсистеме $C \longleftrightarrow O$ монизм превращается в редукционизм, а действие, по отношению к которому общение - лишь форма, ведет не к субъектносубъектному диалогу, а к субъектно-объектному манипулированию. Поэтому В.Н. Сагатовский отмечает, что деятельность может осуществляться лишь в системе<smiles>O[GeH2]</smiles>

Прямо направлены против принципа монизма положения Г.С.Батищева. Они предполагают наличие двух несводимых друг к другу начал - общения как основы творчества и деятельности. «Несводимость», по мнению Г.С.Батищева, выступает здесь в качестве противовеса монистической «сводимости» [1, с.241]. Но сохранить монизм теории, согласно которой всеобщей (и единственной) основой бытия людей является их деятельность, очень трудно, поскольку, как считает автор, еще слабо изучена генетически исходная и первичная форма человеческой деятельности, неразрывность ее общественного характера 
со своеобразно-индивидуальным осуществлением, ее внутреннее единство с творчеством [1, с. 242].

Ю.К.Плетников утверждает, что на уровне социума общение - необходимый компонент и содержание человеческой деятельности, всех ее форм и видов. В общении осуществляется взаимовлияние общественных индивидов, обнаруживается и формируется общность настроений и взглядов, осуществляется передача информации, создаются сплоченность и солидарность, без которых невозможна коллективная деятельность. На уровне же индивида общение само по себе есть вид деятельности [1, с. 273]. Данная точка зрения, на наш взгляд, подтверждается системой субъектно-объектных отношений, предложенной М.С. Каганом, которая включает три типа связей: субъект-объект; субъект-субъект; объект-объект. Графически схема деятельности как система субъект-субъектных и субъект-объектных отношений может выглядеть так:

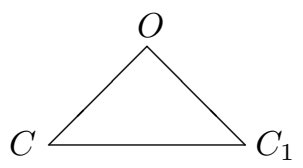

Данная схема помогает увидеть, что общение как межсубъектное отношение не является «безобъектным». Так как субъект и объектпонятия соотносительные, использование одного из них без другого неправомерно. Поэтому, когда говорится о межобъекных отношениях, имеется в виду, что они являются таковыми для познающего или использующего их практически субъекта. Говоря же о межсубъектных отношениях, мы предполагаем их опосредованность объектом - и тем, по поводу которого осуществляется общение, и тем, с помощью которого (как средства, языка, инструмента) оно осуществляется, и тем, который создается совместными усилиями общающихся субъектов. Это значит, что мир объектов не исчезает из сферы межсубъектных отношений. Опосредованность межсубъектных отношений объектами не меняет того решающего обстоятельства, что смысл данной деятельности интерсубъективен. Вот почему, как подчеркивает М.С.Каган, нельзя согласиться с утверждением Я.А. Пономарева, что взаимодействие двух субъектов неизбежно приводит к тому, что «один по отношению к другому выступает в качестве объекта» [3, с. 133]. Общение является таковым до тех пор, пока субъект сохраняет свою субъективность во взаимоотношениях с другим субъектом, а последний ориентируется на своего партнера именно как на партнера по совместной 
деятельности, а не как на объект.

Только увидев это принципиальное различие двух ориентаций активности субъекта, равно необходимых в системе субъектно-объектных отношений, можно раскрыть особенности общения как специфического вида человеческой деятельности, отличающегося от различного рода операций, производимых субъектом с объектами.

Важной закономерностью межсубъектного взаимодействия является также то, что оно оказывается условием и своего рода фундаментом предметной деятельности во всех ее формах, видах и типах. Признать общение основным смыслом и целью деятельности людей, на наш взгляд, неправомерно, так как в одних случаях решающей является ее обращенность на объект, в других - взаимодействие субъектов. Но взаимодействие субъектов выступает в качестве специфического аспекта деятельности, без которого она невозможна.

Таким образом, как нам кажется, решается спор о том, можно ли считать общение конкретным видом деятельности, существующим наряду с другими ее видами - преобразовательной, познавательной, ценностно-ориентационной, или же его следует считать типом деятельности, противостоящим предметной деятельности в целом, как другому ее типу, или же аспектом деятельности, неотделимым от другого ее аспекта - предметного.

По нашему мнению, ответ на этот вопрос не может быть однозначным. Общение может быть и аспектом, и типом, и видом деятельности, в зависимости от функционального характера деятельности. Например, одно дело - общение в трудовом процессе, другое - в дружеской беседе, третье - в научном диспуте. Постоянной остается сама деятельностная природа человеческого общения, проявляющаяся в направленности действий субъекта на другого субъекта.

Переходя к рассмотрению соотношения общения и коммуникации, необходимо отметить, что под влиянием позитивистских настроений понятия «коммуникация» и «общение» стали употребляться как синонимы. Но таково ли на самом деле отношение между ними? По мнению Н.К.Иконниковой, дискуссия о соотношении коммуникации и общения имела место лишь в отечественной литературе (в связи с введением слова - кальки «коммуникация») и ее результаты не могут считаться плодотворными [2, с. 193]. Чтобы согласиться или не согласиться с данной позицией, следует, на наш взгляд, уточнить и проанализировать это понятие, употребляемое как в научной, так и в повседневной практике.

Термин «коммуникация» сравнительно молодой: он появился в на- 
учной литературе в начале XX века и сейчас широко используется в различных смыслах. Сегодня это понятие имеет много значений. Им обозначают общение людей, обмен информацией в обществе, средства сообщений (транспортные коммуникации); этот термин применим и к способам распространения и приема информации (средствами коммуникации являются пресса, почта, кино, телефонная сеть, радио и телевизионные системы, интернет) [6, с.52].

«Коммуникация - социально обусловленный процесс передачи и восприятия информации в условиях межличностного и массового общения по разным каналам при помощи различных коммуникативных средств (вербальных, невербальных и других)» [5, с. 39].

Согласившись с определением Т.В.Науменко, мы будем понимать под коммуникацией процессы перекодировки вербальной в невербальную и невербальной в вербальную сферы. Исторически коммуникацией было именно это: принуждение другого к выполнению того или иного действия. То есть для коммуникации существенен переход от говорения Одного к действиям Другого. На наш взгляд, эти характеристики наиболее подходят для выражения сущности такого социального феномена, как коммуникация; в них улавливается главное в коммуникации - однолинейная направленность информационного воздействия.

Поэтому коммуникация, по нашему мнению, это прежде всего - субъект-объектные отношения. Не всегда этот процесс можно квалифицировать как побуждение другого к выполнению действия. Например, паралингвистический уровень коммуникации (мимика, жесты и т.д.) дает достаточно информации о субъекте коммуникативного акта, но далеко не всегда может расцениваться как побуждение к действию.

Понятие коммуникации существует на двух уровнях - на уровне обыденного и на уровне научного представления об этом явлении. На обыденном уровне под коммуникацией понимается способность к установлению контактов любого рода. Некоторые научные определения коммуникации, при которых она не отделяется от общения, основываются, на наш взгляд, именно на обыденном представлении. Исходя из этого, определяются как сам коммуникативный процесс, так и его участники: «коммуникационное действие - завершенная операция смыслового взаимодействия, происходящая без смены участников коммуникации. Субъектами, вступающими в коммуникацию, могут преследоваться три цели:

1. реципиент желает получить от коммуниканта некоторые привле- 
кательные для него смыслы;

2. коммуникант желает сообщить реципиенту некоторые смыслы, влияющие на поведение последнего;

3. и коммуникант, и реципиент заинтересованы во взаимодействии с целью обмена какими-то смыслами» [5, с.40].

Исходя из этого определения коммуникации, Т.В. Науменко выделяет три формы коммуникативного действия. Подражание-уподобление чему-нибудь или кому-нибудь, присущее первичному уровню социализации, а также характерное для такого коммуникативного действия, как передача традиций и обычаев; диалог - форма взаимодействия равноправных субъектов коммуникации; управление-форма воздействия субъекта на объект.

Предлагаемая автором модель показывает, что при рассмотрении коммуникации как диалога, во-первых, происходит смешение понятий «коммуникация» и «общение», так как диалог-это характеристика общения, а управление - характеристика коммуникации в строгом смысле слова; во-вторых, при этом в самом понятии коммуникации происходит смешение двух уровней ее определения - обыденного и научного, так как подражание, на наш взгляд, не может быть отнесено к коммуникации как таковой и является, по сути, свойством индивида, способствующим его адаптации к среде существования.

Смешение понятий «коммуникация» и «общение» является довольно распространенным и на научном уровне. Часто это смешение происходит по той причине, что перевод английского слова «communication» включает несколько смыслов и может означать передачу, сообщение сведений, информацию, связь, средство связи, а также общение. При использовании перевода этого слова на русский язык происходит смешение двух уровней языковой коммуникации - лингвистического, включающего в себя слова-высказывания, функционирующие в разговорной речи, и металингвистического, включающего слова-термины, лежащие в основе формирования специальных языков различных наук, к числу которых относится и социальная философия.

Основной ролью коммуникации в обществе является социализация посредством передачи информации. Поэтому мы под коммуникацией понимаем информационное воздействие субъекта коммуникации на объект, преследующее цели, заданные субъектом (в данном случае имеется в виду социальная коммуникация, исключающая ее технические аспекты, относящиеся к разряду средств коммуникации). 
Коммуникативный акт, в котором обе его составляющие выступают не как субъект и объект, а как два или несколько заинтересованных друг в друге и взаимодействующих субъекта, называется общением. Коммуникация является необходимым, но недостаточным условием общения, которое, как уже было показано, есть по природе своей не только субъект-объектное отношение, но и субъект-субъектное, характеризующееся выработкой новых духовных значений. Следует отметить, что процесс коммуникации протекает по принципу передачи информации от субъекта к объекту, в то время как общение предполагает взаимодействие субъектов по поводу объекта. Поэтому общение, в отличие от коммуникации, является двусторонним процессом обмена информацией между субъектами коммуникативного акта. Также важно отметить, что в процессе общения за счет обмена и выработки новых духовных значений происходит увеличение объема информации и обогащение ее содержания.

Одна из самых распространенных форм общения - диалог, который в качестве конечного результата предполагает не просто обмен мнениями, а выработку общих позиций по обсуждаемому вопросу либо уточнение позиций друг друга. В процессе коммуникации происходит обратное явление: в силу односторонности передачи информации часть ее содержания утрачивается.

На уровнях межличностного и межгруппового взаимодействия могут совершаться коммуникативные акты, характеризующиеся и как общение, и как коммуникация. Сущность этих актов, способы их осуществления раскрываются Ю. Хабермасом в работе «Теории коммуникативного действия». На место трансцендентального субъекта он выдвигает общество, или «самоконструирующий род». С одной стороны, Ю. Хабермас исходит из реально существующего общества, с другойобращается к идеалу общественных отношений. Последний сводится к интерсубъективному взаимодействию индивидов и допускает достижение истинного согласия участниками коммуникации. Истинное согласие, в свою очередь, требует от участников дискуссии способности отличать бытие от видимости, сущность от явления, сущее от надлежащего, чтобы быть компетентным в вопросах, которые обсуждаются [9, c. 119].

Понятие рода дополняется понятием «идеальной коммуникации». «Идеальная коммуникация», или идеальный дискурс, характеризуется такими факторами: все участники коммуникации - в принципе равноправны, ни один аргумент не должен быть исключен, никто не должен быть ущемлен, используя свои речевые акты. Главную роль играет 
стремление привести наилучший аргумент [7, с. 89].

Таким образом понятие «идеальной коммуникативной общности» Хабермас конкретизирует понятием «неограниченного господства коммуникации», которая направлена на взаимопонимание. Такая коммуникация осуществляется на основе субъект-субъектных отношений и потому требует внимания и уважения к другому, способность слушать и способность говорить.

В речевой коммуникации, где другой выступает как субъект, к мыслям которого прислушиваются и ценности которого разделяют, закладывается основа для восприятия и осознания другого как равноправной и свободной личности, а следовательно - для выхода субъекта за свои собственные границы, «перенятие перспективы» другого, а отсюда, и толерантного отношения к другому.

Этот процесс осуществляется на основе «воли к взаимности», т. е. самоопределения.

Коммуникативный принцип взаимности является этическим принципом, так как рациональное взаимопонимание между людьми немыслимо без нормативного фундамента их взаимного признания как разумных, суверенных и зрелых личностей. В этом - начало и основа морального отношения людей друг к другу $[8$, c. 88]. В этом же-начало и основа общения и деятельности как способа самоосуществления человека, осознания им своей значимости и ценности.

\section{1 Литература}

[1] Деятельность: теории, методология, проблемы.-М.: Политиздат, 1990.

[2] Иконникова H.K. Социальная коммуникация: понятие, символическое содержание (материалы лекций) // Личность. Культура. Общество. - 2001. - Т. III. Вып. 3 (9). - С. 193-206.

[3] Каган М.С. Мир общения: проблемы межсубъектных отношений. - М.: Политиздат, 1988.

[4] Лекторский В.А. Деятельностный подход: смерть или возрождение? // Вопросы философии. - 2001. - № 2. - С. 56-65.

[5] Науменко Т.В. Социология массовых коммуникаций в структуре социального знания // Социс. - 2003. - № 10. - С. 39-46. 
[6] Шарков Ф.И. Истоки и парадигмы исследования социальной коммуникации // Социс. - 2001. - № 8. - С. 52-61.

[7] Habermas J. Moralbewußtsein und kommuinikatives Handeln.Frankfurt a. M., 1983.

[8] Habermas J. Theorie des kommunikativen Handelns. B. 2. Zur Kritik der funktionalistischen Vernunft. - Frankfurt a. M., 1981.

[9] Habermas J. Vorstudien und Ergänzungen zur Theorie des Kommunikativen Handelns. - Frankfurt a. M., 1984. 